\title{
Proanthocyanidins in seed coat's tegmen and endospermic cap inhibit seed germination in Sapium sebiferum
}

\author{
Faheem Afzal Shah ${ }^{1}$, Jun Ni ${ }^{2}$, Jing Chen ${ }^{2}$, Qiaojian Wang ${ }^{1}$, Wenbo Liu ${ }^{2}$, Xue Chen ${ }^{2}$, Caiguo Tang ${ }^{2}$, \\ Songling Fu Corresp., 1, Lifang Wu Corresp. 2 \\ ${ }^{1}$ School of Forestry and Landscape Architecture, Anhui Agriculture University, Hefei, Anhui, China \\ 2 Key laboratory of high magnetic field and Ion beam physical biology, Hefei Institutes of Physical Science, Chinese Academy of Sciences, Hefei, Anhui, \\ China
}

Corresponding Authors: Songling Fu, Lifang Wu

Email address: fusongl001@outlook.com, Ifwu@ipp.ac.cn

Sapium sebiferum, an ornamental and bioenergetic plant, is propagated by seed. Its seed coat contains germination inhibitors and takes a long time to stratify for germination. In this study, we discovered that the $S$. sebiferum seed coat (especially the tegmen) and endospermic cap contained high levels of proanthocyanidins. Seed-coat and endospermic cap removal induced seed germination whereas exogenous application with seed-coat extract or proanthocyanidins significantly inhibited this process, suggesting that proanthocyanidins in the seed coat played a major role in regulating seed germination in S. sebiferum. We further investigated how seed-coat extract affected the expression of the seed-germination-related genes. The results showed that treatment with seed-coat extract upregulated the transcription level of the dormancy-related gene, gibberellins suppressing genes, abscisic acid biosynthesis and signalling genes. Seed-coat extract decreased the transcript levels of abscisic acid catabolic genes, gibberellins biosynthesis genes, reactive oxygen species genes and nitrates-signalling genes. Exogenous application of nordihydroguaiaretic acid, gibberellic acid, hydrogen peroxide and potassium nitrate recovered seed germination in seed-coat-extract supplemented medium. In this study, we highlighted the role of proanthocyanidins, and their interactions with the other germination regulators, in the regulation of seed dormancy in $S$. sebiferum. 


\section{Proanthocyanidins in seed coat's tegmen and endospermic cap inhibit}

\section{2 seed germination in Sapium sebiferum}

3 Faheem Afzal Shah ${ }^{\dagger 1}$, Jun $\mathrm{Ni}^{\dagger 2}$, Jing $\mathrm{Chen}^{2}$, Qiaojian Wang ${ }^{1}$, Wenbo $\mathrm{Liu}^{2}$, Xue Chen ${ }^{2}$, Caiguo

4 Tang ${ }^{2}$, Songling $\mathrm{Fu}^{* 1}$, Lifang $\mathrm{Wu}^{* 2}$

$5{ }^{1}$ School of Forestry and Landscape Architecture, Anhui Agriculture University, Hefei, Anhui,

6 PR China

$7 \quad{ }^{2}$ Key laboratory of high magnetic field and Ion beam physical biology, Hefei Institutes of

8 Physical Science, Chinese Academy of Sciences, Hefei, Anhui 230031, PR China

$9 \dagger$ Authors performed equally to this work.

$10{ }^{*}$ Corresponding Authors: Songling Fu, email: fusong1001@,outlook.com 


\section{Abstract}

Sapium sebiferum, an ornamental and bioenergetic plant, is propagated by seed. Its seed coat contains germination inhibitors and takes a long time to stratify for germination. In this study, we discovered that the $S$. sebiferum seed coat (especially the tegmen) and endospermic cap contained high levels of proanthocyanidins. Seed-coat and endospermic cap removal induced seed germination whereas exogenous application with seed-coat extract or proanthocyanidins significantly inhibited this process, suggesting that proanthocyanidins in the seed coat played a major role in regulating seed germination in S. sebiferum. We further investigated how seed-coat extract affected the expression of the seed-germination-related genes. The results showed that treatment with seed-coat extract upregulated the transcription level of the dormancy-related gene, gibberellins suppressing genes, abscisic acid biosynthesis and signalling genes. Seed-coat extract decreased the transcript levels of abscisic acid catabolic genes, gibberellins biosynthesis genes, reactive oxygen species genes and nitrates-signalling genes. Exogenous application of nordihydroguaiaretic acid, gibberellic acid, hydrogen peroxide and potassium nitrate recovered seed germination in seed-coat-extract supplemented medium. In this study, we highlighted the role of proanthocyanidins, and their interactions with the other germination regulators, in the regulation of seed dormancy in S. sebiferum.

\section{Introduction}

36 Seed germination is an important step in the plant life-cycle because it decides subsequent plant survival and reproductive success. The seed coat can play a role in regulating dormancy. Known mechanisms by which the seed coat regulates dormancy include the prevention of water uptake by an impermeable seed coat, or inhibiting gas exchange (Mcgill et al. 2017), or by mechanically 
40 constraining the embryo, or by containing germination inhibitors (Baskin \& Baskin 2014).

41 Proanthocyanidins (PAs) are the chemical inhibitors of germination found in the seed coat of many

42 plants. As early as 1914, Nilsson-Ehle showed that red seed-coat colour in wheat is associated with

43 extended dormancy period in comparison to that of white-grained wheat. In 1958, Miyamoto \&

44 Everson showed that the red pigment of the seed coat is a substance derived from catechins, which

45 make up PAs. Red seeds of charlock (Sinapis arvensis L.) exhibit a reduced dormancy compared

46 with black seeds (Durán \& Retamal 1989). In legumes, coloured seeds imbibe slower than white

47 seeds and then germinate later (Kantar et al. 1996; Powell 1989; Werker et al. 1979; Wyatt 1977).

48 In Rubus seed PAs contribute to seed-coat hardness and resulting seed dormancy (Wada et al.

2011). In Arabidopsis, the permeability and thickness of the testa are affected by the PAs and some

50 structural elements altered in mutants, which may lead to effects on germination (Debeaujon et al.

51 2000). The seeds need GAs to overcome the dormancy imposed by the seed coat (Debeaujon \&

52 Koornneef 2000). PAs located in the seed coat can act as a doorkeeper to seed germination.

53 Inhibitory effect of PAs on seed germination is due to de novo biogenesis of ABA. Compared with

54 wild-types, PAs deficient mutants contain a lower concentration of ABA during germination. PAs

55 regulation of seed germination is mediated by the ABA signalling pathway (Himi et al. 2002;

56 Liguo et al. 2012). PAs modulate the activities of the Class III peroxidase that controlled the levels

57 of reactive oxygen species (ROS) during seed germination (Jia et al. 2013; Jia et al. 2012).

Chinese tallow (Sapium sebiferum L.) belongs to the Euphorbiaceae family and is native to eastern Asia (Esser 2002). It is popular because of its colourful autumn foliage (Zhao \& Tao 2015). The white waxy aril of the seeds contains highly saturated fatty acids and highly unsaturated oil is found in the seed (Boldor et al. 2010). Tallow has been used for manufacturing soap, candles, 
63 al. 1987; Jeffrey \& Padley 1991). A single mature tree of S. sebiferum produces many seeds. The

64

65

estimated yield of a $S$. sebiferum tree is 4,700 litres of oil per hectare every year which far exceeds the average commercial yields of traditional oilseed crops (Boldor et al. 2010; Webster et al. 2006). That is why, S. sebiferum has recently become a species of interest as a source of biodiesel (Gao et al. 2016)

Sexual propagation is an easy method of commercial propagation, and it's being used widely for the commercial propagation of a large number of plant species, including many bio-energetic plants like S. sebiferum. However, the poor rate of seed germination due to deep dormancy has seriously limited its use (Li et al., 2011).

S. sebiferum seeds have hard, dark brown to blackish seed outer testa and reddish brown inner tegmen. The tegmen encloses the endosperm, which in turn encloses the embryo. Tallow tree seeds readily imbibed water but the seed coat at the site of the radicle appeared to be a barrier to seed germination. Germination of cabbage seeds was inhibited when cabbage seeds were soaked in extracted solutions from $S$. sebiferum seed coat (Li et al. 2012). Moreover, it has also been discovered that endosperm extracts have a stronger inhibitory effect on cabbage seed germination than seed coat extracts of S. sebiferum (Qian et al. 2016). We hypothesize that germination inhibitors found in S. sebiferum could be the PAs. It is currently unknown which layer of the seed coat has the highest concentration of PAs? PAs inhibit seed germination by influencing ABA, GA and ROS regulatory genes (Debeaujon \& Koornneef 2000; Debeaujon et al. 2000; Jia et al. 2013; Jia et al. 2012; Liguo et al. 2012). Nitrates also play an important role during seed germination (Lara et al. 2014). It is unclear whether PAs response to nitrate signalling. We tested whether exogenous application of an ABA biosynthesis inhibitor nordihydroguaiaretic acid (NDGA), gibberellic acid $\left(\mathrm{GA}_{3}\right)$, hydrogen peroxide $\left(\mathrm{H}_{2} \mathrm{O}_{2}\right)$ and potassium nitrate $\left(\mathrm{KNO}_{3}\right)$ promote seed 
86 germination is the presence of seed coat extract (SCE, which may contain PAs inside)? We

87 conducted several experiments to address these questions, to test our hypothesis, and to

88 demonstrate the mechanism involved in S. sebiferum seed dormancy.

\section{Materials and methods}

\section{Seed material collection and storage}

91 S. sebiferum seeds were harvested from six plants grown in the experimental field of Hefei Institute of Physical Science, Chinese Academy of Sciences ( $\left.31^{\circ} 52^{\prime} 0^{\prime \prime} \mathrm{N}, 117^{\circ} 17^{\prime} 0^{\prime \prime} \mathrm{E}\right)$, Anhui, China. Hefei has a humid subtropical climate with four different seasons. According to Anhui meteorological bureau, Hefei's annual average temperature is $16.2^{\circ} \mathrm{C}$. Hefei's annual average low temperature is $12.6^{\circ} \mathrm{C}$. Summers are hot and humid, with a July average of $28.3^{\circ} \mathrm{C}$. Its annual precipitation is over 1000 millimetres. Seeds were collected in December 2016 from six trees, filled in nylon bags, and stored at room temperature prior to use. The experiment was conducted from March to October 2017.

\section{Chemicals and stock solutions}

The $\mathrm{GA}_{3}$ (CAS\# 77-06-5), NDGA ( $\geq 97 \%$, CAS\# 500-38-9), and Vanillin (CAS\# 121-33-5) were purchased from Sigma Aldrich (Shanghai) Trading Co., Ltd. $\mathrm{KNO}_{3}\left(\mathrm{CAS} \#\right.$ 7757-79-1), $\mathrm{H}_{2} \mathrm{O}_{2}$ (30\%, CAS\# 7722-84-1), sulfuric acid $\left(\mathrm{H}_{2} \mathrm{SO}_{4}, \mathrm{CAS} 7664-93-9\right)$ and Hydrochloric acid (HCl, hypochlorite (NaClO, CAS\# 7681-52-9) was bought from Sangon Biotech (Shanghai) Co., Ltd. A pure supply of proanthocyanidins (UV $\geq 95 \%$, CAS 4852-22-6) was purchased from Shanghai Aladdin Biochemical Technology Co., Ltd. Ethanol (99.7\%, CAS\# 64-17-5) and methanol (99.7\%, 
107 CAS\# 67-56-1) was purchased from Shanghai, Titan Scientific Co., Ltd. China). Sodium 108 hydroxide (NaOH, CAS\# 1310-73-2) was purchased from Shanghai Chemical Reagent Co., Ltd. 109 Murashige and Skoog (MS) medium was purchased from Qingdao Hope Bio-Technology Co., 110 Ltd. Shandong, China. The $\mathrm{GA}_{3}$ and NDGA stock solutions $(100 \mathrm{mM})$ were prepared by dissolving 111 in $80 \%$ methanol. $\mathrm{KNO}_{3}$ stock solution (10\%) was prepared by dissolving in distilled water. All 112 stock solutions were diluted in distilled water to make working solutions.

\section{Seed-coat extraction, application, and PAs analysis}

114 Seed-coat extract was prepared as described by Li et al. (2012) with little modification. $S$. 115 sebiferum tree seed coats were ground into powder. Ten-grams of seed-coat powder was dissolved 116 in $200 \mathrm{~mL}$ of $80 \%(\mathrm{v} / \mathrm{v})$ aqueous methanol and placed in a refrigerator at $4.0^{\circ} \mathrm{C}$ for 24 hours. After 117 centrifugation (by BECKMAN COULTER, Allegra X-30R Centrifuge) at $4500 \mathrm{rpm}$ at $4.0^{\circ} \mathrm{C}$ for 11810 minutes, the supernatant was evaporated under vacuum at $40.0^{\circ} \mathrm{C}$.

SCE and PAs medium for growing seeds were prepared by using $0.1 \%, 0.2 \%$, and $0.3 \%$ seed coat extract and pure proanthocyanidins in $0.5 \times$ Morashige and Skoog medium (MS) containing $15 \mathrm{~g} / \mathrm{L}$ sucrose and $8 \mathrm{~g} / \mathrm{L}$ agar before sterilization. All media were autoclaved at $121.0^{\circ} \mathrm{C}$ for 22 minutes and poured into $9 \mathrm{~cm}$ diameter Petri dishes $(20 \mathrm{ml}$ each) under a laminar flow hood. Seedcoat proanthocyanidin contents were analyzed by conventional $\mathrm{HCl}-$ vanillin assay (Herald et al. 2014).Seed coat was ground under liquid nitrogen by a YLK Ball Mill Machine (YLT-04), And $30 \mathrm{mg}$ seed-coat powder was extracted for $20 \mathrm{~min}$ in $5 \mathrm{~mL} 1 \% \mathrm{HCl}$ in methanol at $30.0^{\circ} \mathrm{C}$ in a water bath. The extracts were centrifuged at $4500 \mathrm{rpm}$ for $5 \mathrm{~min}$. One $\mathrm{mL}$ aliquots of the extract were dispensed into two culture tubes designated as sample and sample control. The tubes were 
129 prepared daily by mixing equal amounts of $1 \%$ vanillin with $8 \% \mathrm{HCl}$ solutions. Five ml of the

130 working vanillin reagent was added at $1 \mathrm{~min}$ intervals to the extract, and $5.0 \mathrm{~mL}$ of $4 \% \mathrm{HCl}$ was

131 added to the sample control. The prepared tubes were incubated in a water bath at $30.0^{\circ} \mathrm{C}$ for

132 exactly $20 \mathrm{~min}$, after which the absorbance was measured at $500 \mathrm{~nm}$ using nano-spectrophotometer

133 of ScanDrop 100 (Analytik Jena AG, Germany). Final absorbance was calculated by subtracting

134 the absorbance of the sample control from the corresponding vanillin-containing sample. Standard

135 curves were developed using pure proanthocyanidins (UV $\geq 95 \%$ ) at concentrations that ranged

136 from 0 to $100 \mu \mathrm{g} / \mathrm{mL}$. Endospermic cap's proanthocyanidins were analyzed by the previously used

137 protocol as described by Xuan et al. (2014). Decoated seeds were dipped in 1\% vanillin with 8\%

$138 \mathrm{HCl}$ solution and incubated in a water bath at $30.0^{\circ} \mathrm{C}$ for 20 minutes. Photographs were taken by

139 an Olympus SZX10 stereomicroscope having a TUCSEN 6.0 megapixel USB 2.0 colour camera.

\section{Pre-germination treatments and germination conditions}

141 Seeds were washed with 1\% sodium hydroxide for removing white tallow. Sulfuric acid scarification was done by dipping seed in $98.08 \%$ concentrated sulfuric acid at $4.0^{\circ} \mathrm{C}$ for $10-, 20-$, 30-, 40-, 50-, and 60 minutes. After each time period of sulfuric acid treatment, seeds were washed in running tap water five times. For mechanical scarification, a cut was made by scissors in the seed coat on the opposite side of the radical. Intact seeds and scarified seeds were sown separately in five replicates (ten seeds in each pot) in $10 \times 10 \mathrm{~cm}$ pots containing peat moss. We investigated the water uptake of intact seed and sulfuric acid scarified seed using the method of Li et al. (2012).

The seed coat was removed by dissection leaving the embryo (embryonic axis and endosperm) as a single unit, hereafter referred to as a 'decoated seed'. We used decoated seed to verify PAs and seed-coat extract's effects. Decoated seeds were sterilized by washing two times with $70 \%$ ethyl 
151 alcohol for 30 seconds and then incubated in $20 \% \mathrm{NaClO}$ for 10 minutes. After rinsing off $\mathrm{NaClO}$,

152 the seeds were washed three times with autoclaved water and dried by blotting over sterilized filter

153 papers. For the endospermic cap (ESC) experiments, ESC was removed with a sterilized blade in

154 a laminar flow hood.

155 Sterilized decoated seeds were sown in SCE and PAs mediums. To investigate the relationship

156 of seed-coat's proanthocyanidins with GA-, ABA-, ROS-, and nitrates- signalling genes, we

157 primed the decoated seeds in sterile water (for control), $\mathrm{GA}_{3}(50 \mu \mathrm{M}), \mathrm{NDGA}(50 \mu \mathrm{M}), \mathrm{H}_{2} \mathrm{O}_{2}(20$

$158 \mathrm{mM})$ and $0.4 \% \mathrm{KNO}_{3}$ separately overnight (12 hours) at room temperature $\left(25.0^{\circ} \mathrm{C}\right)$ and sowed

159 the primed seed in $0.5 \times \mathrm{MS}$ medium supplemented with $0.3 \%$ SCE. Germination conditions for all

160 experiments were maintained as day/night temperatures of $25.0 / 20.0{ }^{\circ} \mathrm{C}$, with 16 - hours light/8

161 hours dark photoperiod, $150 \mu \mathrm{mol} \mathrm{m}-2 / \mathrm{s}$ photosynthetic photon flux density and $70 \%$ relative

162 humidity. Protrusion of the radical from the micropyle was considered as the standard for seed

163 germination. Germination data were recorded every day after germination started (five days after

164 imbibition). Shoot and root length were measured manually with a ruler. All seed germination

165 pictures were taken by NIKON D90 containing NIKON DX AF-S NIKKOR 18-105 mm lens.

166 Primer designing, RNA extraction, cDNA synthesis, and RT-qPCR conditions

167 The full sequences of all genes were obtained by local blasting Arabidopsis amino-acids sequence

168 in blast-2.2.31. A local blast library was built by flower-bud transcriptome (Accession:

169 SRX656554, https://www.ncbi.nlm.nih.gov/sra/SRX656554) of S. sebiferum (Yang et al. 2015).

170 Lists of all gene's full mRNA sequences is available in S. Data 1. Primers used for qPCR were

171 designed by using primer premier 6 . The $\mathrm{T}_{\mathrm{m}}$ of the primers was between 59.0 and $61.0^{\circ} \mathrm{C}$ and a

172 list of all primers are given in S. Table 1. For gene expression analysis, seed samples were taken 
173 the $3^{\text {rd }}$ and $6^{\text {th }}$ day after imbibition. Samples were frozen in liquid nitrogen and stored at $-80.0^{\circ} \mathrm{C}$.

174 RNA was extracted by using E.Z.N.A® plant RNA extraction kit (OMEGA Pro -TEK) according

175 to the given protocol. Five hundred ng RNA of each sample was reverse transcribed using cDNA

176 synthesis SuperMix (TransGen Biotech.) according to the given protocol. The cDNA samples were

177 diluted $25 \mathrm{X}$ with sterile water. For each qPCR, $9 \mu 1$ of the sample, $10 \mu \mathrm{l}$ of the $2 \mathrm{X}$ QuantiNova

178 SYBR Green PCR Master Mix (QIAGEN) and $0.5 \mu$ of each primer was added to make a final

179 volume of $20 \mu \mathrm{l}$. The RT-qPCRs were run on a Light Cycler®96 (Roche). The qPCR program run

180 consisted of the first step at $95.0^{\circ} \mathrm{C}$ for three min and afterwards 45 cycles alternating between 15

$181 \mathrm{sec}$ at $95.0^{\circ} \mathrm{C}, 15 \mathrm{sec}$ at $60.0^{\circ} \mathrm{C}$ and $15 \mathrm{sec}$ at $72.0^{\circ} \mathrm{C}$.

182 Statistical analysis

183 All data was arranged in Excel 2013 and statistical analyses were done in R Studio 1.1.383. All

184 data were represented with mean \pm standard deviation. Results from the different treatments were 185 analysed separately. The significance of treatments was tested by one-way analysis of variance 186 (ANOVA). Duncan's multiple range test and the Tukey test were used to identify significant 187 differences between pairs of means at $\mathrm{P}<0.05$.

\section{Results}

\section{Sulfuric acid scarification promotes seed germination}

190 We found that sulfuric acid digested the seed coat external surface and caused cracks. Ten and 20 191 minutes incubation time digested the epidermal layer of the seed coat while the 30-, 40-, and 50

192 minutes incubation caused mild cracks in the seed coat. But the 60 minutes incubation in sulfuric 193 acid caused deep cracks in seed coat (Fig. 1A). When we measured the proanthocyanidins contents 
194 of 0-, 10-, 20-, 30-, 40-, 50-, and 60 minutes scarified seed, we found that sulfuric acid scarification

195 degraded the PAs contents is proportional to incubation time (Fig. 2).

196 We investigated the water uptake of intact seed and sulfuric-acid scarified seed. Water uptake 197 of untreated control seeds was $16.5-17.8 \%$ over 72 hours; seeds treated with sulfuric acid for longer 198 periods of time showed increasing water uptake to a maximum of $22.5 \%$ after 60 minutes of acid 199 treatment. Our results showed that water uptake gradually increased from untreated (control) 0 to 20010 minutes, 20-, 30-, 40-, 50-, and 60 minutes. Water uptake percentages of 20-, 30-, 40-, 50-, and 20160 minutes scarified seed were significantly different from the control, but the water uptake 202 percentage of 10- minutes scarified was not significantly different from control (Fig. 1B). We 203 found that germination of intact seeds was $2 \%$, and ranged from $40-65 \%$ in sulfuric-acid-scarified 204 seeds while mechanically scarified showed 20\% germination in 20 days. (Fig. 1C, S. Fig. 1). Intact 205 and scarified seed's germination were significantly different $(\mathrm{P}=0.05)$. When we measured the root and shoot length of seedling of 45-day-old seedlings, we found that the seedlings whose seeds were chemically scarified by 30-, 40-, and 50 minutes incubation in sulfuric acid, had more root and shoot length than the seedlings of 0-, 10-, 20- and 60 minutes incubated seeds in sulfuric acid.

(Fig. $1 \mathrm{C}$ and D).

Tegmen and endospermic cap contained proanthocyanidins which inhibited seed germination

212 From germination analysis, we found that the decoated seeds showed $85 \pm 5 \%$ seed germination

213 within seven days (Fig. 3B and S. Fig. 2). Seed coat extract (SCE) supplemented medium inhibited seed germination (Fig. 3B). We determined proanthocyanidins concentration in S. sebiferum seed coat's testa and tegmen separately and also SCE. We found that testa and tegmen contain $3 \pm 2 \%$ 
216 and $65 \pm 5 \%$ (mean $\pm \mathrm{sd})$ of proanthocyanidins respectively, while SCE contained $30 \pm 3 \%$ (mean $\pm \mathrm{sd}$ )

217 proanthocyanidins (Fig. 3A). We also tested seed germination in proanthocyanidins-supplemented

$2180.5 \times \mathrm{MS}$, the results showed that proanthocyanidins significantly inhibited the seed germination in

219 S. sebiferum (Fig. 3B).

Further, we found that the seeds of $S$. sebiferum contain a dark brownish colour endospermic cap (ESC). When cultivated on $0.5 \times \mathrm{MS}$, we found that dark brownish ESC became darker in some dormant seeds (Fig. 4A). When we removed that ESC and cultivated those ESC removed seed on $0.5 \times \mathrm{MS}$, we found the seed without ESC showed $100 \%$ seed germination within five days which was significantly different than the seed with ESC (Fig. 4B and 4C). We hypothesized that the dark brownish ESC might accumulate proanthocyanidins, which inhibited seed germination. Then we determined proanthocyanidins by vanillin assay, and, interestingly we found that ESC gives red colour which is an indication of proanthocyanidins. We also tested the dynamic changes in PAs in ESC of intact seeds cultivated in peat moss media. We found that the intensity of proanthocyanidins gradually decreased with imbibition time, and, after complete diminishing of proanthocyanidins in ESC, the seed showed signs of germination (Fig. 4D).

\section{Effect of seed-coat extract on the expression level of dormancy-related genes}

We examined the relationship between the seed coat dormancy and the expression levels of GA-, ABA-, ROS-, and nitrates-related genes. To investigate whether this effect was because of PAs, we compared the relative expression of GA-, ABA-, ROS-, nitrates-, and dormancy-related genes between the control, SCE and PAs treatments. It is very important to check the expression of dormancy-specific genes while studying seed dormancy. Delay of Germination 1 (DOG1) is a 
238 al. 2017). We found that the expression level of SsDOG1 was significantly higher in SCE and PAs

239 as compared to control on the $3^{\text {rd }}$ and $6^{\text {th }}$ day of imbibition. But the expression level of SsDOG1 at

240 both time points was not significantly different between SCE and PAs (Fig. 5A).

241 It has been reported that dormant seed has high levels of ABA (Millar et al. 2010). To find

242 the transcriptional changes of ABA-related genes during different imbibition periods of different

243 treatments, we selected 9-cis-epoxycarotenoid dioxygenases 6 (NCED6), INSENSITIVE3 (ABI3),

244 and CYP707A2 as ABA biosynthesis, signalling and catalyzing genes respectively (Dekkers et al.

245 2016; Footitt et al. 2011). We also found that PAs and SCE both promoted the expression level of

246 SsNCED6 on both $3^{\text {rd }}$ and $6^{\text {th }}$ day of imbibition (Fig. 5B). In SCE and PAs, the SsCYP $707 A 2$

247 expression decrease gradually with time, while in the control $S s C Y P 707 A 2$ expression is higher

248 during both $3^{\text {rd }}$ and $6^{\text {th }}$ day of imbibition (Fig. 5C). Expression levels of $S s A B I 3$ were not

249 significantly different between control, PAs, and SCE on the $3^{\text {rd }}$ day of imbibition. Interestingly,

250 on the $6^{\text {th }}$ day of imbibition, the $S S A B I 3$ expression level remained the same in SCE and PAs but

251 dropped in the control (Fig. 5D).

252 Gibberellins (GAs) are plant hormones that play an important role in seed germination. we 253 selected a GA-biosynthesis gene (GA3OX1), a GA-inactivating gene (GA2OX), GA negative 254 regulator genes GAI (GIBBERELLIC ACID INSENSITIVE) and RGL2 (REPRESSOR-OF-GA1 2)

255 (Lee et al. 2002; Matsushita et al. 2007; Ravindran et al. 2017; Rieu et al. 2008; Shen et al. 2016).

256 PAs and SCE significantly repressed the $S s G A 3 O X 1$ expression level as compared to the control 257 on the $3^{\text {rd }}$ day, while $S s G A 3 O X 1$ transcript remained unchanged on the $6^{\text {th }}$ day in both SCE and 258 PAs. Expression levels of $S S A B I 3$ were not significantly different between control, PAs, and SCE 259 on the $3^{\text {rd }}$ day of imbibition. Interestingly, on the $6^{\text {th }}$ day of imbibition, the $S s A B I 3$ expression level 260 remained the same in SCE and PAs but dropped in the control (Fig. 5D). In PAs and SCE, the 
261 expression level of $S s G A 2 O X$ increased on the $3^{\text {rd }}$ day and then decreased non-significantly on the

$2626^{\text {th }}$ day of imbibition (Fig. 6A). In the control treatment, $S s G A 2 O X$ transcription decreased

263 gradually with time (Fig. 6C). SsRGL2 and $S s G A I$ expression levels were higher in SCE and PAs

264 as compared to the control during both the $3^{\text {rd }}$ and the $6^{\text {th }}$ day of imbibition (Fig. 6B and D

265 respectively).

266 Reactive oxygen species (ROS) are highly active during seed germination. MITOGEN267 ACTIVATED PROTEIN KINASE $(M P K s)$ protein regulates the ROS signalling. Among the $M P K s$

268 genes, MPK6 is highly active during seed germination (Oracz et al. 2009; Oracz \& Karpinski

269 2016). In our experiments, the effects of PAs and SCE were negative on SsMPK6 transcription.

270 Relative expression of the SSMPK6 decreased over time in the seed growing on SCE and PAs. On

271 the other hand, in the control treatment, the transcription levels of the SSMPK6 increased from the

$2723^{\text {rd }}$ to the $6^{\text {th }}$ day of imbibition (Fig. 7A).

273 Among the soil nutrients, nitrates play an important role in seed germination with a specific

274 molecular mechanism (Lara et al. 2014). To investigate the impact of seed coat on nitrates 275 signalling, we selected nitrates-signalling genes NIN-LIKE-PROTEIN 8 (NLP8) and CBL276 INTERACTING PROTEIN KINASE 23 (CIPK23) (Footitt et al. 2017; Yan et al. 2016). The 277 transcript level of SSNLP8 was higher in the control as compared to PAs and SCE treatments in 278 both $3^{\text {rd }}$ and the $6^{\text {th }}$ day of imbibition (Fig. 7B). PAs and SCE treatments decreased the expression 279 level of SsCIPK23 gradually as compared to the control on both the $3^{\text {rd }}$ and 6 th imbibition day 280 (Fig. 7C).

We found interactions of seed-coat's PAs with the germination regulators. After seven days 282 imbibition, the control, $\mathrm{GA}_{3}, \mathrm{NDGA}, \mathrm{H}_{2} \mathrm{O}_{2}$ and $\mathrm{KNO}_{3}$ priming showed $36 \pm 4.8,97.22 \pm 4.8,91.9 \pm 1$, 
$28393.44 \pm 3$ and $97.22 \pm 4.8($ mean \pm sd) percent germination respectively on $0.5 \times$ MS medium

284 supplemented with $0.3 \%$ SCE. We found that all of our treatments significantly $(\mathrm{P}=0.05)$ promoted

285 germination as compared to the control (Fig. 8 and S. Fig. 3).

\section{Discussion}

287 The data presented here show the causes of dormancy in S. sebiferum seed. PAs found in the seed

288 coat and the endospermic cap were the major controllers of dormancy in S. sebiferum seed. Our

289 results show that $S$. sebiferum intact seeds are dormant, imbibe water, and increase in germination

290 if the covering structures such as the seed coat and endosperm cap are removed. Seeds showing

291 this combination of features fit into the non-deep physiological dormancy category of Baskin \&

292 Baskin (2014). The causes of dormancy in these seeds can lie in the covering structures like seed

293 coat (Baskin \& Baskin 2014) and endospermic cap. If the covering structures control dormancy,

294 there are a number of known mechanisms by which they do so; they can be impermeable to water,

295 they can mechanically constrain the embryo from germinating, can contain chemical inhibitors of

296 germination, and can prevent the exit of chemical inhibitors of germination present in the embryo.

297 S. sebiferum intact seeds take up water, and so the seed coat is permeable to water. These results

298 are in agreement with the results of Li et al. (2012). Recently, Mcgill et al. (2017) also reported

299 that the rapid uptake of water within the first hour of imbibition indicates that the M. hortensia

300 seed coat is not acting as a water impermeable barrier preventing germination,which suggests that

301 water impermeability is not the reason of dormancy in S. sebiferum seed.

302 In our study, if the seed coat is removed, germination does increase substantially, as would be

303 predicted from the model that the seed coat could have mechanical constraints. Our results show

304 that mechanical scarification can slightly break the seed dormancy but scarification with sulfuric 
305 acid which degrades the germination inhibitors greatly improves germination. These results

306 suggest that any mechanical constraint by the seed coat on germination is minor, compared to the

307 major role played by germination inhibitors in the seed coat. Our results are agreement with the

308 results of Wada et al. (2011), which showed that the effectiveness of sulfuric acid for Rubus seed

309 scarification was likely due to degradation of PAs in the testa. The acid both weakened the seed

310 coat and degraded the inhibitors (PAs) which the seed coat contains, and these inhibitors restrict

311 germination of decoated seeds. Our results suggest that covering structures like tegmen contain

312 germination inhibitors. These inhibitors restrict germination of decoated seeds, so removal of the

313 seed coat results in $85 \%$ germination of the decoated seeds. The endospermic cap also contains

314 inhibitors, and the removal of the endospermic cap results in $100 \%$ germination. It is also possible

315 that the endospermic cap is mechanically restraining the extra $15 \%$ of seeds from germinating, but

316 the evidence we present here (vanillin assay) about the changes in the colour of the endospermic

317 cap support the chemical inhibition model.

318 Proanthocyanidins found in the tegmen and the endospermic cap are the inhibitors of seed

319 germination in S. sebiferum and have a molecular mechanism to inhibit seed germination. In our

320 study, SCE (containing PAs) and pure PAs treatments impacted the expression level of genes

321 involved in GA/ABA homeostasis, which suggests that the seed-coat induced the seed dormancy

322 by influencing on transcription levels of ABA and GA biosynthesis or degradation genes and

323 unbalance between GA/ABA homeostasis (Debeaujon \& Koornneef 2000; Debeaujon et al. 2000;

324 Liguo et al. 2012). Seeds primed in $\mathrm{GA}_{3}$ and NDGA recovered seed germination on SCE

325 supplemented medium conforms the above-suggested model. ROS and nitrates are also important

326 factors in seed germination due to their role in the maintenance of $\mathrm{ABA} / \mathrm{GA}$ homeostasis

327 (Debeaujon \& Koornneef 2000; Jia et al. 2012; Lara et al. 2014; Liu et al. 2010; Yan et al. 2016; 
328 Zhou et al. 2015). Exogenous application of PAs and SCE in growing medium significantly

329 reduced the transcription level of ROS- and nitrates-signalling genes. $\mathrm{H}_{2} \mathrm{O}_{2}$ - and $\mathrm{KNO}_{3}$ - primed

330 seed recovered the germination on SCE-containing medium. These results are agreement with

331 previously reported results that a mutation of Arabidopsis with transparent testa 8 (TT8) lacked

332 PAs accumulation in its testa, produced a high level of $\mathrm{H}_{2} \mathrm{O}_{2}$ after imbibition, and had higher

333 germination rate (Jia et al. 2013; Liu et al. 2010). $\mathrm{H}_{2} \mathrm{O}_{2}$ is the main kind of ROS in plants which

334 regulates seed germination through GA / ABA metabolism and signalling, (Jia et al. 2013; Jia et

335 al. 2012; Liu et al. 2010). KNO3 is a source of nitrates which activate the nitrate reductase enzyme

336 and regulate the expression of nitrates-signalling genes NLP8 and CIPK23 which induce seed

337 germination. NLP8 binds directly to the promoter of CYP707A2 and reduces abscisic acid levels

338 in a nitrate-dependent manner (Footitt et al. 2017; Liu et al. 2010; Yan et al. 2016).

\section{Conclusion}

340 Our research offers a quick and easy method for germinating S. sebiferum seeds for nursery

341 growers. Moreover, this experiment will provide a basis for researchers to understand the

342 mechanisms involved in $S$. sebiferum seed dormancy. S. sebiferum seeds contain

343 proanthocyanidins in the seed coat (tegmen layer) and endospermic cap. PAs impact the

344 transcription of ABA-, GA-, ROS-, and nitrates-related genes, and cause dormancy in S. sebiferum

345 seed. In our experiments, we found dynamic changes in PAs levels in the endospermic cap. To

346 generalize this result, more investigations from seeds of other species are required.

\section{Acknowledgements}

348 The authors are thankful to Ghulam Ali Bugti, school of plant protection, Anhui Agriculture

349 University, for providing his wise suggestions for improving the quality of manuscript. 
350

351

352

353

354

355

356

357

358

359

360

361

362

363

364

365

366

367

368

369

370

371

\section{References}

Baskin C, and Baskin JM. 2014. Seeds: Ecology, Biogeography, and Evolution of Dormancy and Germination. San Diego: Academic Press

Boldor D, Kanitkar A, Terigar BG, Leonardi C, Lima M, and Breitenbeck GA. 2010. Microwave assisted extraction of biodiesel feedstock from the seeds of invasive chinese tallow tree. Environmental Science \& Technology 44:4019-4025.

Brooks G, Morrice NA, Ellis C, Aitken A, Evans AT, and Evans FJ. 1987. Toxic phorbol esters from Chinese tallow stimulate protein kinase C. Toxicon Official Journal of the International Society on Toxinology 25:1229-1233.

Debeaujon I, and Koornneef M. 2000. Gibberellin requirement for Arabidopsis seed germination is determined both by testa characteristics and embryonic abscisic acid. Plant Physiology $122: 415-424$.

Debeaujon I, Leon-Kloosterziel KM, and Koornneef M. 2000. Influence of the testa on seed dormancy, germination, and longevity in Arabidopsis. Plant Physiology 122:403-414.

Dekkers BJ, He H, Hanson J, Willems LA, Jamar DC, Cueff G, Rajjou L, Hilhorst HW, and Bentsink L. 2016. The Arabidopsis DELAY OF GERMINATION 1 gene affects ABSCISIC ACID INSENSITIVE 5 (ABI5) expression and genetically interacts with $A B I 3$ during Arabidopsis seed development. The Plant Journal 85:451-465.

Durán JM, and Retamal N. 1989. Coat structure and regulation of dormancy in Sinapis arvensis L. Seeds. Journal of Plant Physiology 135:218-222.

Esser H-J. 2002. A revision of Triadica Lour.(Euphorbiaceae). Harvard Papers in Botany 7:1721. 
372 Footitt S, Douterelo-Soler I, Clay H, and Finch-Savage WE. 2011. Dormancy cycling in

373 Arabidopsis seeds is controlled by seasonally distinct hormone-signaling pathways.

374

375 Proceedings of the National Academy of Sciences of the United States of America 108:20236-20241.

Footitt S, Olcer-Footitt H, Hambidge AJ, and Finch-Savage WE. 2017. A laboratory simulation of Arabidopsis seed dormancy cycling provides new insight into its regulation by clock genes and the dormancy-related genes DOG1, MFT, CIPK23 and PHYA. Plant Cell and Environment 40:1474-1486.

Gao RX, Su ZS, Yin YB, Sun LN, and Li SY. 2016. Germplasm, chemical constituents, biological activities, utilization, and control of Chinese tallow (Triadica sebifera (L.) Small). Biological Invasions 18:809-829.

Herald TJ, Gadgil P, Perumal R, Bean SR, and Wilson JD. 2014. High-throughput micro-plate HCI-vanillin assay for screening tannin content in sorghum grain. Jounal of the Science of Food and Agriculture 94:2133-2136.

Himi E, Mares DJ, Yanagisawa A, and Noda K. 2002. Effect of grain colour gene (R) on grain dormancy and sensitivity of the embryo to abscisic acid (ABA) in wheat. Journal of Experimental Botany 53:1569.

Jeffrey BSJ, and Padley FBJ. 1991. Chinese vegetable tallow-characterization and contamination by stillingia oil. Journal of the American Oil Chemists Society 68:123-127.

Jia L, Xu W, Li W, Ye N, Liu R, Shi L, Bin Rahman AN, Fan M, and Zhang J. 2013. Class III peroxidases are activated in proanthocyanidin-deficient Arabidopsis thaliana seeds. Annals of Botany 111:839-847. 
394 Jia LG, Sheng ZW, Xu WF, Li YX, Liu YG, Xia YJ, and Zhang JH. 2012. Modulation of anti-

395 oxidation ability by proanthocyanidins during germination of Arabidopsis thaliana seeds. $396 \quad$ Molecular Plant 5:472-481.

397 Kantar F, Pilbeam CJ, and Hebblethwaite PD. 1996. Effect of tannin content of faba bean (Vicia $398 \quad f a b a$ ) seed on seed vigour, germination and field emergence. Annals of Applied Biology 128:85-93.

400

401

402

403

404

405

406

407

408

409

410

411

412

413

414

Lara TS, Lira JMS, Rodrigues AC, Rakocevic M, and Alvarenga AA. 2014. Potassium nitrate priming affects the activity of nitrate reductase and antioxidant enzymes in tomato germination. Journal of Agricultural Science 6:72-80.

Lee SC, Cheng H, King KE, Wang WF, He YW, Hussain A, Lo J, Harberd NP, and Peng JR. 2002. Gibberellin regulates Arabidopsis seed germination via $R G L 2$, a GAI/RGA-like gene whose expression is up-regulated following imbibition. Genes \& Development $16: 646-658$.

Li SX, Gu HB, Mao Y, Yin TM, and Gao HD. 2012. Effects of tallow tree seed coat on seed germination. Journal of Forestry Research 23:229-233.

Liguo, Qiuyu, Nenghui, Weifeng, Rubaiyath, Rahman, Yiji, Jianhua, and Zhang. 2012. Proanthocyanidins inhibit seed germination by maintaining a high level of abscisic acid in Arabidopsis thaliana. Journal of Integrative Plant Biology 54:663-673.

Liu Y, Ye N, Liu R, Chen M, and Zhang J. 2010. $\mathrm{H}_{2} \mathrm{O}_{2}$ mediates the regulation of ABA catabolism and GA biosynthesis in Arabidopsis seed dormancy and germination. Journal of Experimental Botany 61:2979-2990. 
415 Matsushita A, Furumoto T, Ishida S, and Takahashi Y. 2007. AGF1, an AT-hook protein, is

416

417

418

419

420

421

422

423

424

425

426

427

428

429

430

431

432

433

434

435

necessary for the negative feedback of AtGA3oxl encoding GA 3-oxidase. Plant Physiology 143:1152-1162.

Mcgill CR, Park MJ, Williams WM, Outred HA, and Nadarajan J. 2017. The mechanism of seed coat-imposed dormancy revealed by oxygen uptake in Chatham Island forget-me-not Myosotidium hortensia (Decne.) Baill. New Zealand Journal of Botany 56:1-13.

Millar AA, Jacobsen JV, Ross JJ, Helliwell CA, Poole AT, Scofield G, Reid JB, and Gubler F. 2010. Seed dormancy and ABA metabolism in Arabidopsis and barley: the role of $A B A$ 8' -hydroxylase. The Plant Journal 45:942-954.

Miyamoto T, and Everson EH. 1958. Biochemical and physiological studies of wheat seed pigmentation. Agronomy Journal 50:733-734.

Nilsson-Ehle H. 1914 Zur kenntnis der mit der keimungsphysiologie des weizens in zusammenhang stehenden inneren faktoren. Z Pflanzenzu“cht 2:153-187.

Oracz K, El-Maarouf-Bouteau H, Kranner I, Bogatek R, Corbineau F, and Bailly C. 2009. The mechanisms involved in seed dormancy alleviation by hydrogen cyanide unravel the role of reactive oxygen species as key factors of cellular signaling during germination. Plant Physiology 150:494-505.

Oracz K, and Karpinski S. 2016. Phytohormones signaling pathways and ROS involvement in seed germination. Frontiers in Plant Science 7:864-869.

Powell AA. 1989. The importance of genetically determined seed coat characteristics to seed quality in grain legumes. Annals of Botany 63:169-175. 
436 Qian CM, Zhou J, Chen L, Su YY, Dai S, and Li SX. 2016. Bioassay of germination inhibitors in

437

438

439

440

441

442

443

444

445

446

447

448

449

450

451

452

453

454

455

456

457

458

extracts of Sapium sebiferum seeds of different provenance. Journal of Horticultural Science \& Biotechnology 91:341-346.

Ravindran P, Verma V, Stamm P, and Kumar PP. 2017. A novel RGL2-DOF6 complex contributes to primary seed dormancy in Arabidopsis thaliana by regulating a GATA transcription factor. Molecular Plant 10:1307-1320.

Rieu I, Eriksson S, Powers SJ, Gong F, Griffiths J, Woolley L, Benlloch R, Nilsson O, Thomas SG, and Hedden P. 2008. Genetic analysis reveals that C19-GA 2-oxidation is a major gibberellin inactivation pathway in Arabidopsis. The Plant Cell 20:2420-2436.

Shen C, Wang X, Zhang L, Lin S, Liu D, Wang Q, Cai S, Eltanbouly R, Gan L, and Han W. 2016. Identification and characterization of tomato gibberellin 2-oxidases (GA2oxs) and effects of fruit-specific SlGA2oxl overexpression on fruit and seed growth and development. Horticulture Research 3:16059-16068.

Wada S, Kennedy JA, and Reed BM. 2011. Seed-coat anatomy and proanthocyanidins contribute to the dormancy of Rubus seed. Scientia Horticulturae 130:762-768.

Webster CR, Jenkins MA, and Jose S. 2006. Woody invaders and the challenges they pose to forest ecosystems in the eastern United States. Journal of Forestry 104:366-374.

Werker E, Marbach I, and Mayer AM. 1979. Relation between the anatomy of the testa, water permeability and the presence of phenolics in the genus Pisum. Annals of Botany 43:765771.

Wyatt JE. 1977. Seed coat and water absorption properties of seed of near-isogenic snap bean lines differing in seed coat color. Journal American Society for Horticultural Science 102:478-480. 
459 Yan D, Vanathy E, Vivian C, Masanori O, Matthew I, Mitsuhiro K, Akira E, Ryoichi Y, Asher 460 P, and Gong Y. 2016. NIN-like protein 8 is a master regulator of nitrate-promoted seed germination in Arabidopsis. Nature Communications 7:13179-13190.

462 Yang M, Wu Y, Jin S, Hou J, Mao Y, Liu W, Shen Y, and Wu L. 2015. Flower bud

463

464

465

466

467

468

469

470

471 transcriptome analysis of Sapium sebiferum (Linn.) Roxb. and primary investigation of drought induced flowering: Pathway construction and G-Quadruplex prediction based on transcriptome. Plos One 10:e118479.

Zhao D, and Tao J. 2015. Recent advances on the development and regulation of flower color in ornamental plants. Frontiers in Plant Science 6:261-274.

Zhou J, Yin YT, Qian CM, Liao ZY, Shu Y, and Li SX. 2015. Seed coat morphology in Sapium sebiferum in relation to its mechanism of water uptake. Journal of Horticultural Science \& Biotechnology 90:613-618. 


\section{Figure 1}

Sulfuric acid (SA) scarification significantly promoted the seed germination of Sapium sebiferum.

A, Effect of SA scarification time on seed coat; red arrows indicate the bruises, scars and cracks caused by SA. Bars $1 \mathrm{~mm}$. B, SA impacts on water uptake in the seed. C, SA-induced seed germination of S. Sebiferum. D and E, Impact of SA on shoot and root length of seedlings respectively. Shoot and root length were measured after 45 days of imbibition. Data shown are means $\pm s d(n=3)$. Means with different letters are significantly different at $P$ $<0.05$ using Duncan's multiple range HSD post hoc test. The photographs were taken by Shah Faheem Afzal and Jun Ni.

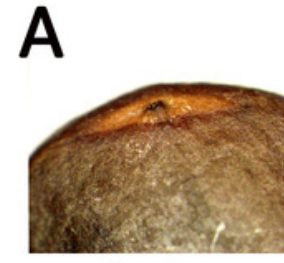

Control

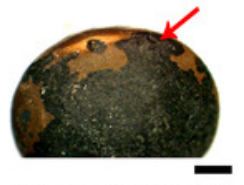

20 Minutes in $\mathrm{H}_{2} \mathrm{SO}_{4}$

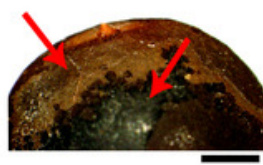

40 Minutes in $\mathrm{H}_{2} \mathrm{SO}_{4}$

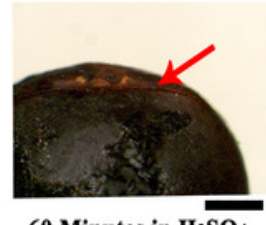

60 Minutes in $\mathrm{H}_{2} \mathrm{SO}_{4}$

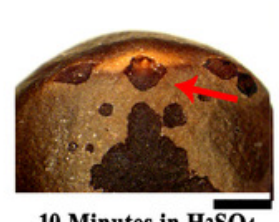

10 Minutes in $\mathrm{H}_{2} \overline{\mathrm{SO}_{4}}$

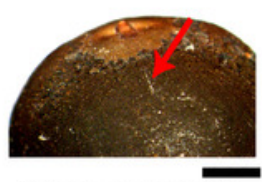

30 Minutes in $\mathrm{H}_{2} \mathrm{SO}_{4}$

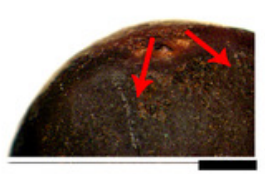

50 Minutes in $\mathrm{H}_{2} \mathrm{SO}_{4}$

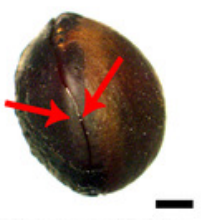

60 Minutes in $\mathrm{H}_{2} \mathrm{SO}_{4}$
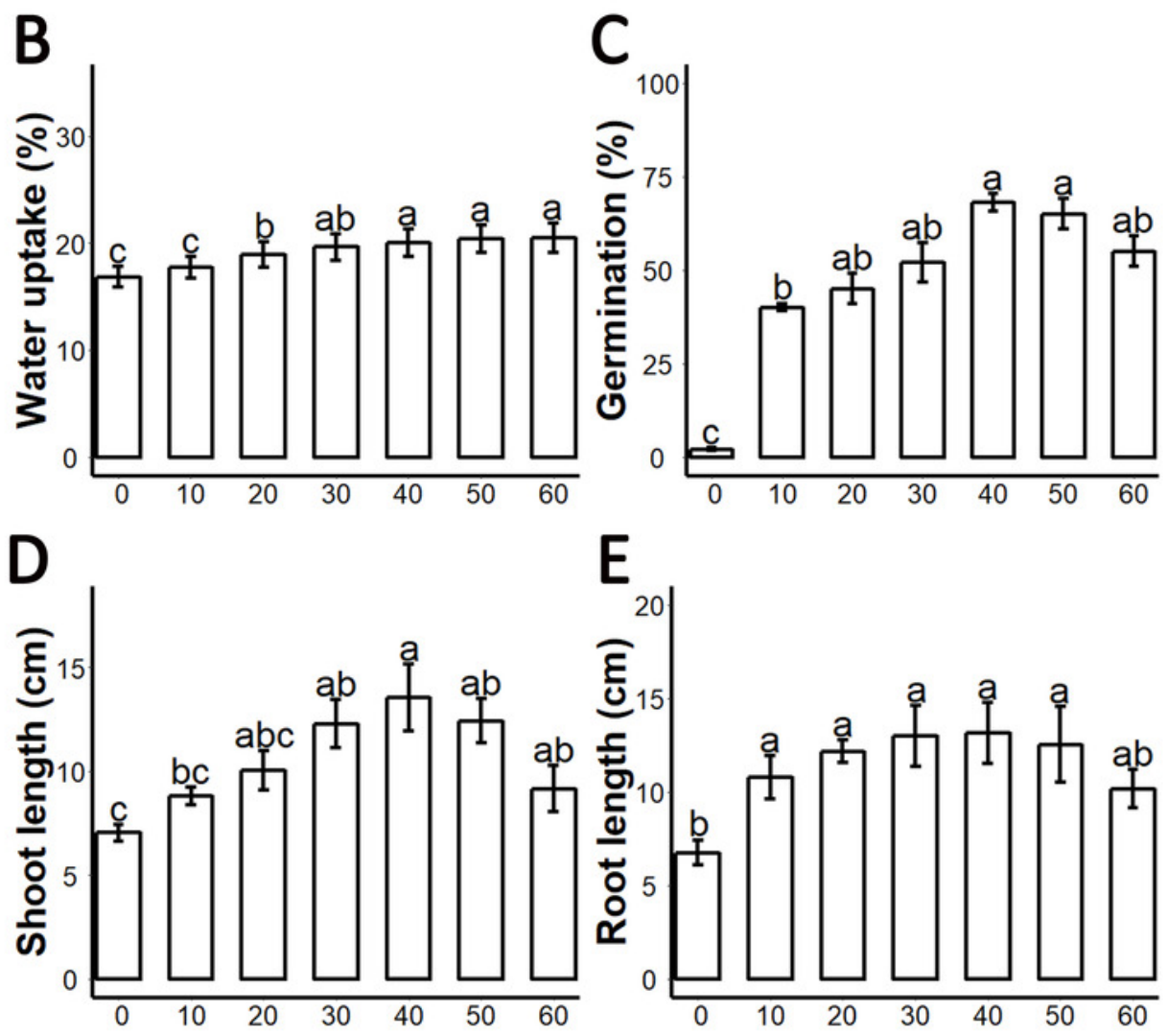

Scarification time (minutes) 
Figure 2

Impact of sulfuric acid scarification on PAs contents of S. Sebiferum seed coat.

Seeds of S. Sebiferum were dipped in concentrated sulfuric acid for 10, 20,30, 40, 50, and 60 minutes separately. PAs contents of acid-scarified seeds were determined by vanillin assay. Data shown are means $\pm s d(n=3)$. Means with different letters are significantly different at $P$ $<0.05$ using Tuckey's HSD post hoc test. 


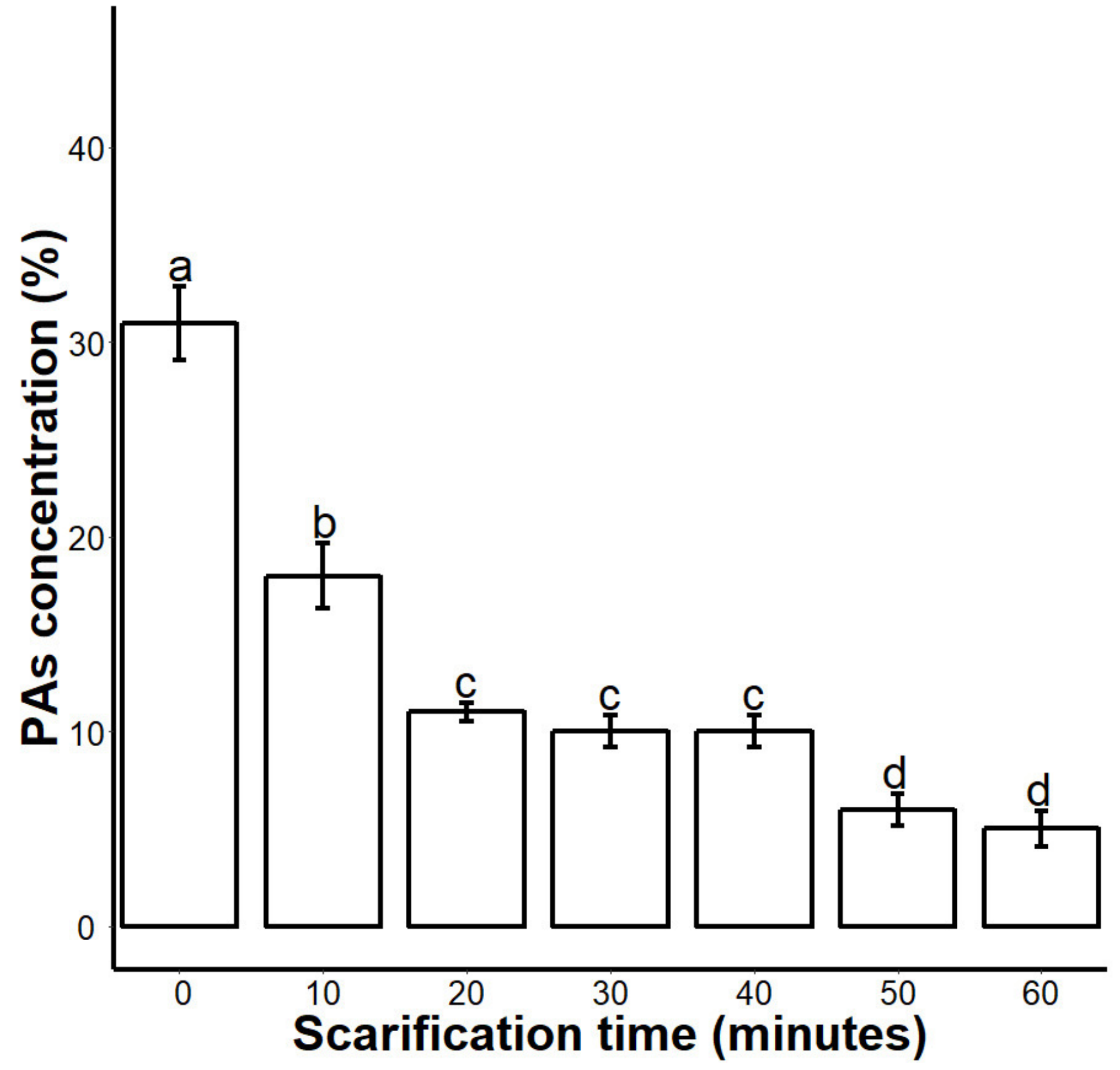




\section{Figure 3}

Impacts of exogenous application of SCE and PAs on seed germination.

A, PAs contents in SCE, tegmen and testa of S. Sebiferum seed coat. B, Impact of different concentrations of SCE and PAs on seed germination. Data shown are means $\pm s d(n=3)$.

Means with different letters are significantly different at $P<0.05$ using Tuckey's HSD post hoc test. 


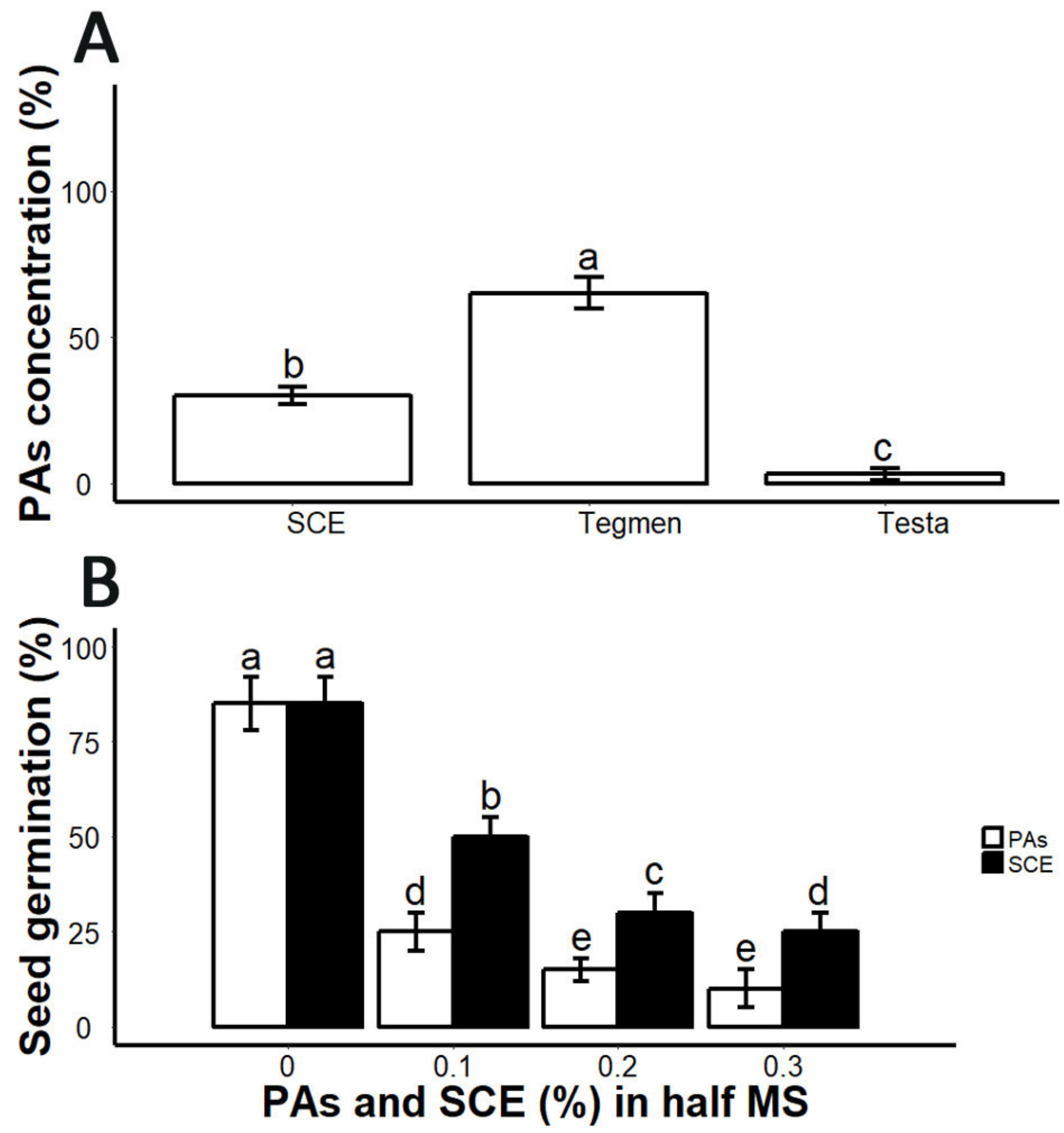


Figure 4

PAs in the endospermic cap affected the seed germination.

A, Accumulantion of PAs in endospermic cap of dormant seed. B and C, Decaping of endospermic cap significantly promoted seed germination as compared to control (with endospermic cap). D, Dynamic changes of PAs in the endospermic cap of non-dormant seed. Bars in $\mathbf{A}$ and $\mathbf{D} 2 \mathrm{~mm}$. B $1 \mathrm{~cm}$. The photographs were taken by Shah Faheem Afzal.

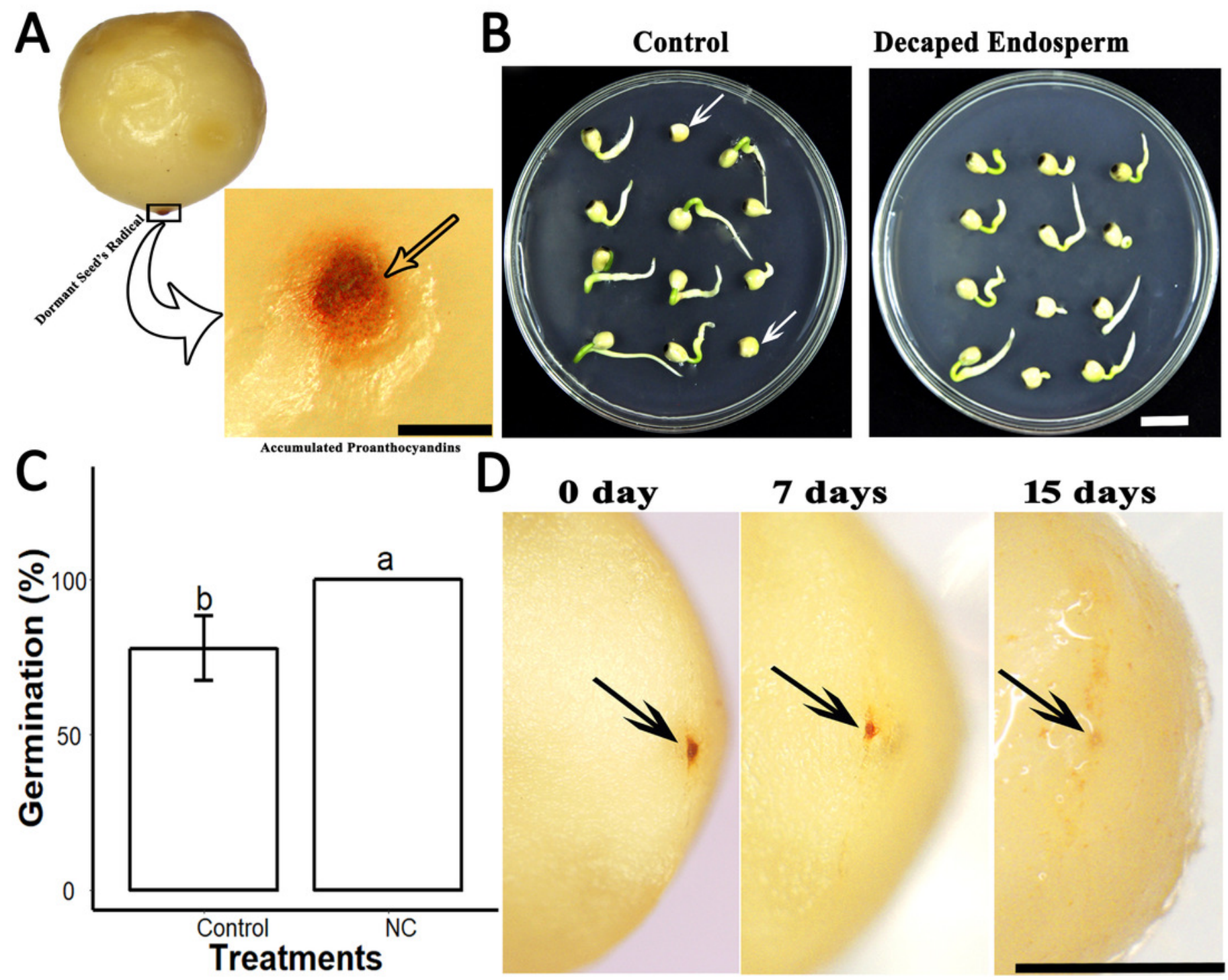




\section{Figure 5}

Effect of SCE on the expression of seed dormancy-related gene (SSDOG1) and ABArelated genes.

The expression of SsDOG1, SsNCED6, SsCYP707A2 and SSABI3 were determined by qRT-PCR on $3^{\text {rd }}$ and $6^{\text {th }}$ day after treatment. SSACTIN was used as the reference gene. Control, seed grown in half MS medium. PAs, proanthocyanidins-supplemented half MS medium. SCE, half MS medium supplemented with seed coat extract. Data shown are means $\pm s d(n=3)$. Means with different letters are significantly different at $P<0.05$ using Tuckey's HSD post hoc test. 


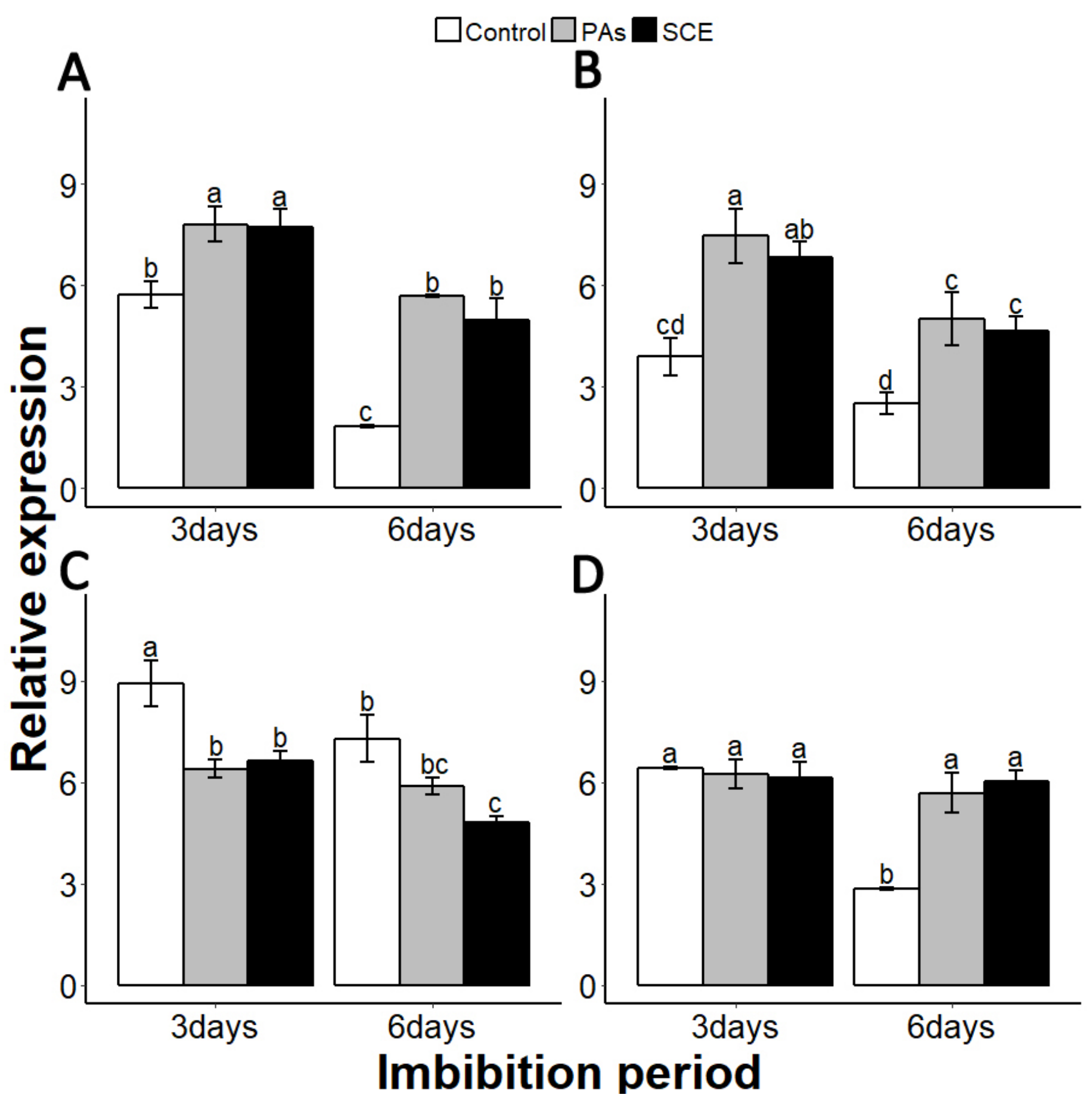




\section{Figure 6}

Effect of SCE on the expression of GA-related genes.

The expression of SSGA3OX1, SsGAOX, SsRGL2, and SsGAl was determined by qRT-PCR on $3^{\text {rd }}$ and $6^{\text {th }}$ day after treatment. SSACTIN was used as the reference gene. Control, seed grown in half MS medium. PAs, proanthocyanidins-supplemented $(0.1 \%)$ half MS medium. SCE, half MS medium supplemented with seed coat extract $(0.3 \%)$. Data shown are means $\pm s d(n=3)$. Means with different letters are significantly different at $P<0.05$ using Tuckey's HSD post hoc test. 


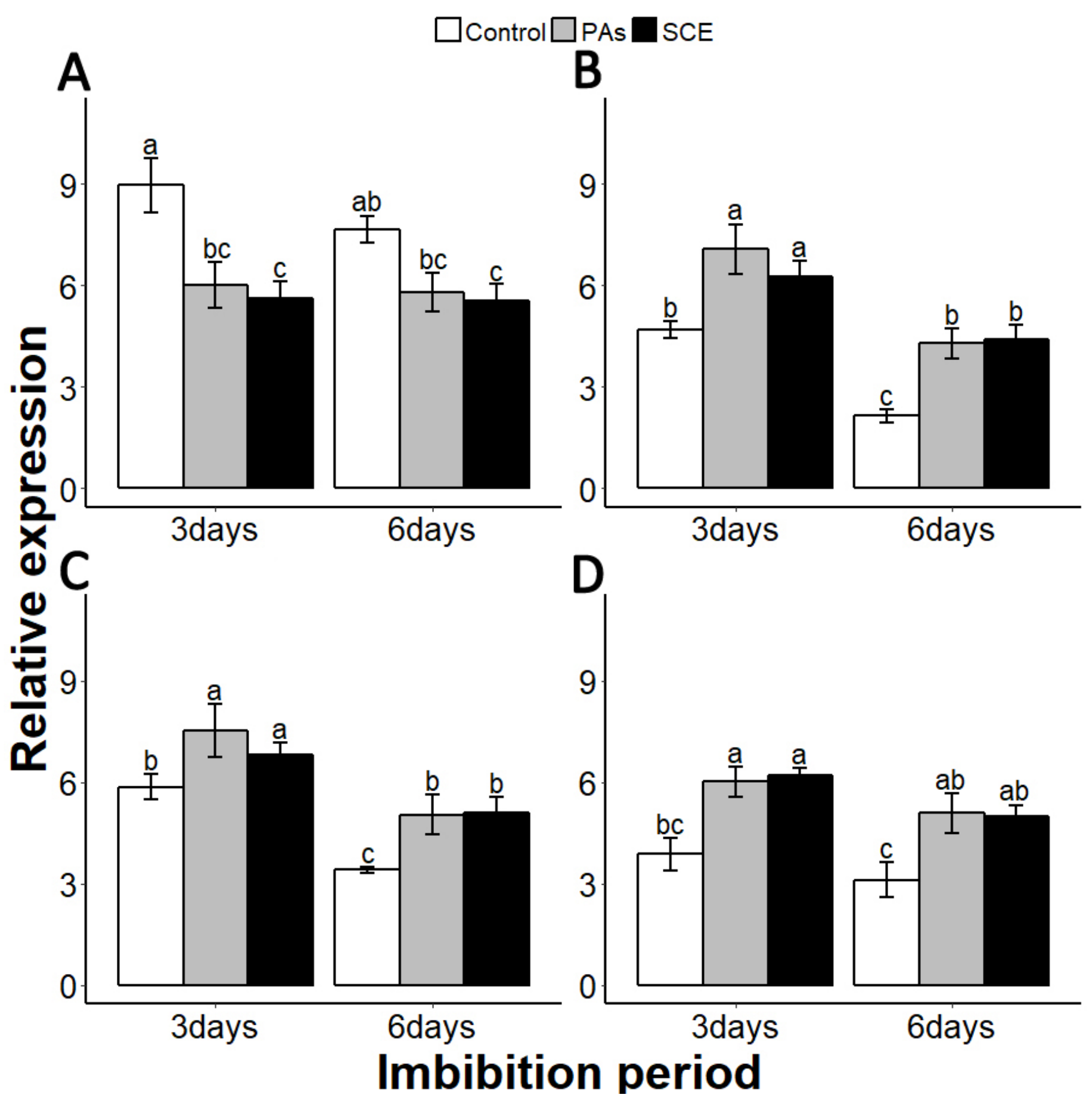




\section{Figure 7}

Impact of SCE on expression levels of ROS- and nitrates-signalling genes.

The expression of SSMPK6, SSNLP8 and SsCIPK23 were determined by qRT- PCR on the $3^{\text {rd }}$ and $6^{\text {th }}$ day after treatment. SSACTIN was used as the reference gene. Control, seeds grown in half MS medium. PAs, proanthocyanidins-supplemented half MS medium. SCE, seeds cultivated on half MS medium supplemented with seed coat extract. Data shown are means $\pm s d(n=3)$. Means with different letters are significantly different at $P<0.05$ using Tuckey's HSD post hoc test. 


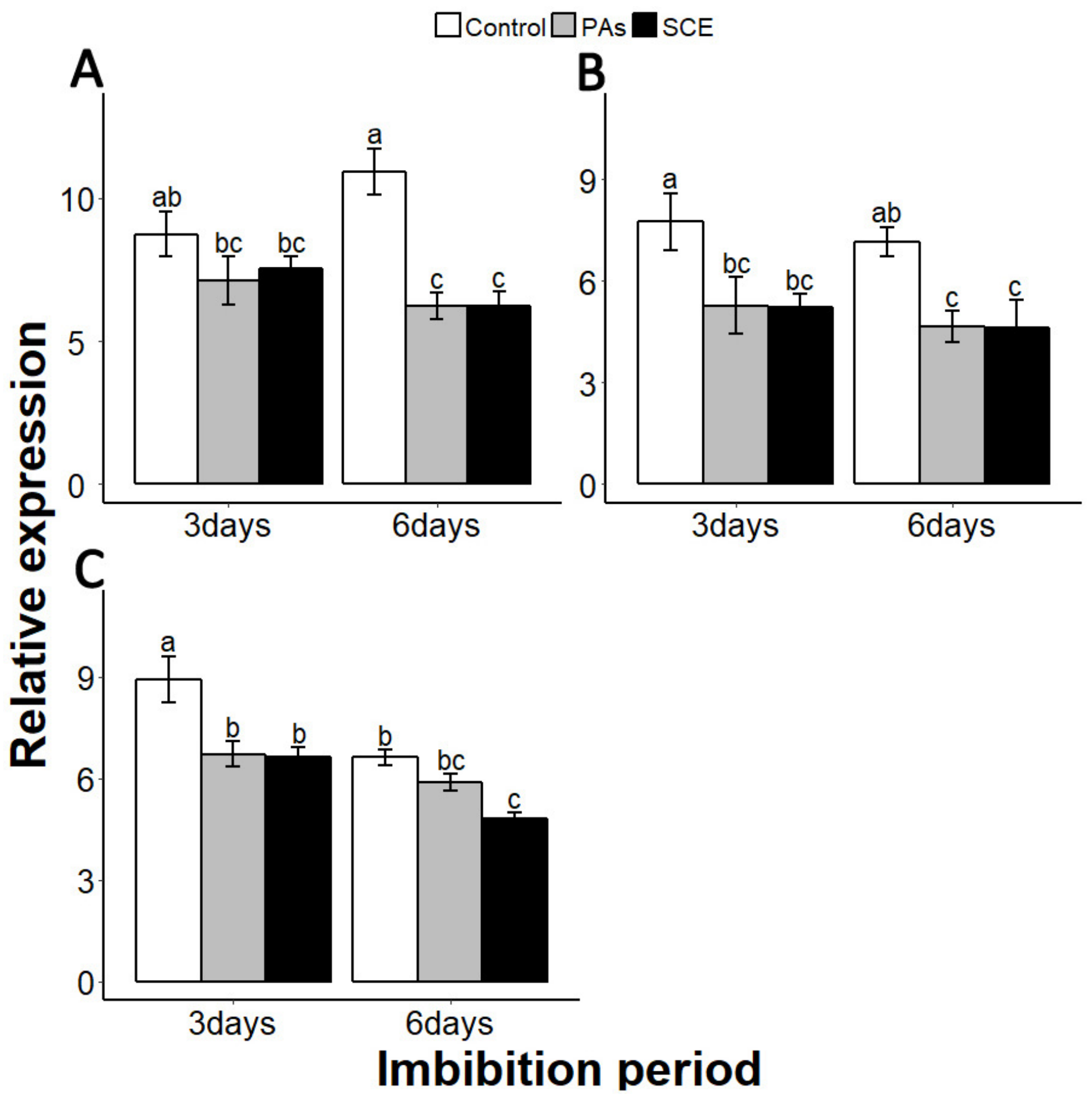




\section{Figure 8}

Inhibitory effects of SCE on seed germination was alleviated by $\mathrm{GA}_{3}, \mathrm{NDGA}, \mathrm{H}_{2} \mathrm{O}_{2}$ and $\mathrm{KNO}_{3}$

Seeds were primed in double distilled water (Control), $50 \mu \mathrm{M} \mathrm{GA}, 50 \mu \mathrm{M} \mathrm{NDGA}, 20 \mathrm{mM} \mathrm{H}_{2} \mathrm{O}_{2}$ and $0.4 \% \mathrm{KNO}_{3}$ and were sowed in $0.3 \% \mathrm{SCE}$-supplemented half MS medium. The seed germination rate was recorded seven days after imbibition. Data shown are means \pm sd $(n=3)$. Means with different letters are significantly different at $P<0.05$ using Tuckey's HSD post hoc test. 


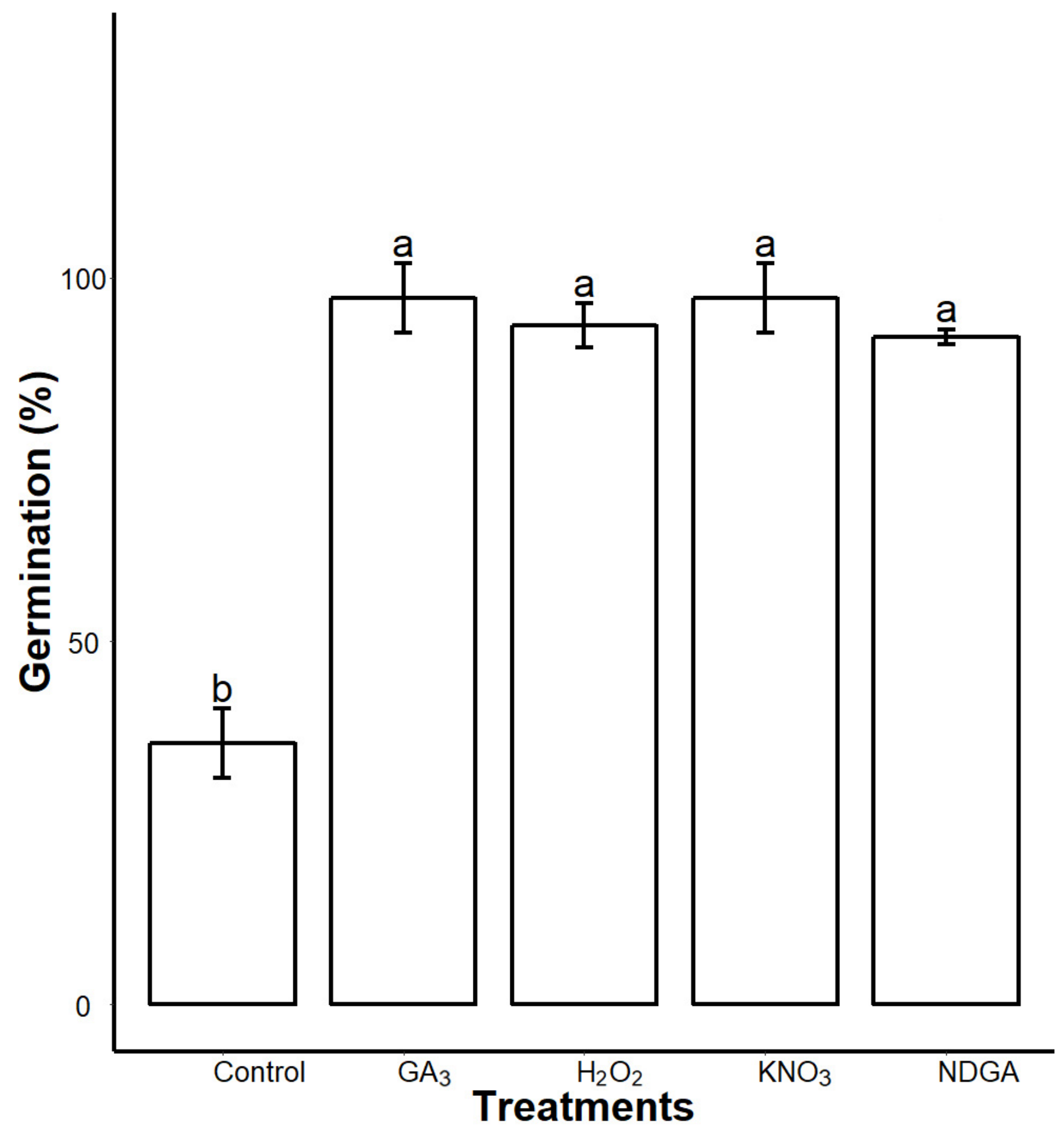

